\title{
Abdominal Ureter
}

National Cancer Institute

\section{Source}

National Cancer Institute. Abdominal Ureter. NCI Thesaurus. Code C160617.

The segment of the ureter that extends from the renal pelvis to the iliac vessels. 